\title{
WANDA DE AGUIAR HORTA BIOGRAFIA
}

Júnla VIllela Gonçalves"

GONÇALVES, J. V. Wanda de Aguiar Horta: biografia. Rev. Esc. Enf. USP, São Paulo,

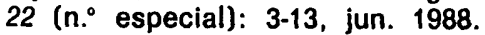

Neste trabalho tentou-se reconstruir os principais fatos da vida profissional de Wanda de Aguiar Horta, cuja atuação como enfermeira e educadora revolucionou a estrutura conceitual da enfermagem brasileira. Como introdução foi feita uma revisão da metodologia do gênero biográfico.

UNITERMOS: Wanda de Aguiar Horta. Blografia.

\section{INTRODUÇÃO}

O objetivo deste trabalho é divulgar a vida e obra de Wanda de Aguiar Horta, eminente mestra falecida em 1981.

Sua influência no ensino da enfermagem no Brasil é evidente. O estudo de sua obra faz parte dos currículos de todas as escolas de graduação em enfermagem do Brasil.

Sua mensagem ultrapassou não só as fronteiras geográficas, sendo estudada também a nível internacional, como também venceu as barreiras do tempo permanecendo ainda viva e atual.

Decorridos seis anos de seu falecimento, seu trabalho ainda serve de marco referencial para inúmeras pesquisas em enfermagem.

Wanda de Aguiar Horta buscou ao longo de sua trajetória criar e transmitir um conceito de enfermagem que englobasse os aspectos, muitas vezes conflitantes, de arte humanitária, ciência e profissão.

Não foi tarefa fácil, no seio de uma profissão fortemente marcada por estereótipos. Enfrentou uma série de resistências, o que só fez engrandecer o seu trabalho.

Do ponto de vista histórico, o estudo de sua obra é estimulante. Deixou farta documentação de seu trabalho, inúmeras publicações em

\footnotetext{
- Enfermeira do Hospital Infantil Menino Jesus da Prefeitura Municipal de Săo Paulo. Aluna do Curso de Pós-Graduação. Nível de Mestrado da Escola de Enfermagem da USP.
} 
periódicos, muitos originais não publicados que utilizava como material didático e um livro onde procurou sintetizar seus estudos, o Processo de Enfermagem.

Sem dúvida Wanda de Aguiar Horta foi uma dessas personalidades que merecem a atenção dos historiadores. Essas personalidades, segundo BESSELAR $^{2}$, são aquelas que se insurgem contra as tendências niveladoras de toda comunidade humana, influenciando assim o processo histórico pelo seu valor intrínseco e pelas mudanças que produzem.

Para melhor compreensão da real dimensão da obra de Wanda de Aguiar Horta, em extensão e profundidade, este estudo foi dividido em três partes:

1. Introdução.

2. Notas sobre metodologia do trabalho biográfico.

Embora não exista uma fórmula geral para a elaboração de trabalhos neste gênero, procurou-se levantar na literatura existente alguns princípios e preceitos com a finalidade de dar um suporte teórico ao trabalho.

Sem ter a pretensão de se constituir em uma estrutura conceitual bem definida, estas notas podem, porém, servir de guia para a leitura da unidade 3.

3. Vida e obra de Wanda de Aguiar Horta - é o núcleo central desta pesquisa, para o qual as partes anteriores contribuem como elementos acessórios.

\section{METODOLOGIA DO TRABALHO BIOGRÁFICO}

O trabalho histórico se reveste de algumas características peculiares que merecem certas considerações.

Reconstituir fatos ocorridos no passado e organizá-los em forma de narrativa é algo que ocorre com freqüência no dia a dia de todas pessoas.

No entanto, quando se trata de uma pesquisa científica, é necessário que para cada fato relatado exista documentação que o comprove.

No caso deste trabalho, não tendo a autora conhecido pessoalmente Wanda de Aguiar Horta, o relato de sua vida e experiência profissional foi baseado nas seguintes fontes:

- Relatos de contemporâneos

- familiares

- alunos

- colegas

- Publicações em periódicos

- Revista Brasileira de Enfermagem - 16 artigos, de 1964 a 1979.

- Revista da Escola de Enfermagem da USP - 11 artigos e 3 editoriais, de 1968 a 1979. 
- Revista Enfermagem em Novas Dimensões - 13 artigos e 22 editoriais de 1975 a 1979.

- O Processo de Enfermagem

- Livro publicado pela autora em 1970.

- Notas de aula e material didático

- Vasto acervo pertencente à Escola de Enfermagem da USP.

Organizá-las, de forma a transmitir a verdadeira dimensão do trabalho de Wanda de Aguiar Horta como educadora, se constitui no ponto principal desta pesquisa.

Lytton STRACHEY ${ }^{11}$ no prefácio de seu livro Vitorianos Eminentes, faz algumas considerações sobre a metodologia do trabalho histórico:

"É evidente que a história não é uma acumulação de fatos, mas a organização destes em forma de narrativa. Se são reunidos sem arte, se tornam uma compilação e as compilações, sem dúvida, podem ser úteis, mas não são história, assim como ovos, tempero e manteiga por si só não são uma omelete".

Mais adiante, no mesmo prefácio, ele se refere especificamente ao trabalho biográfico:

"Não é necessário entrar em detalhes. O biógrafo deve se ater a uma brevidade decente, que exclui tudo que é redundante e não omite nada que é significativo. Este é seu primeiro dever. O segundo, é o de guardar sua própria liberdade de espírito - o biógrafo deve apresentar os fatos como ele os vê".

Mais tarde, BESSELAR ${ }^{2}$ em sua introdução aos estudos históricos, faz aproximadamente as mesmas recomendações:

"A verdade deve orientar o biógrafo a cada passo. Porém a verdade absoluta está fora do alcance humano. Se o biógrafo relata apenas fatos documentados e documentáveis, torna-se enfadonho e pedante. Quem tiver a pretensão de descrever a vida de uma pessoa humana não deve perder o contato vital com o homem. Deve ter uma visão de seu herói e ser capaz de transmiti-la a seus leitores; uma visão necessariamente pessoal embora não arbitrariamente subjetiva; que transcenda os fatos documentados e ao mesmo tempo nunca os perca de vista; uma visão que se baseie no estudo dos documentos conquanto que seja capaz de tirar deles um rico conteúdo humano".

O genero biográfico tem sido cultivado desde a antigüidade e pelos mais diversos processos. Ora são acumulados dados exteriores de modo a construir um verdadeiro quadro da época em que viveu o biografado, ora é feita a análise psicológica de sua figura. Sob o verbete "biografia", ENCYCLOPAEDIA BRITANNICA ${ }^{4}$ diz: "Além de historiador, o biógrafo tem que ser um retratista. A biografia é um retrato de uma alma em suas aventuras através da vida". 
A respeito destas "aventuras da alma", é interessante fazer ligação com as considerações de BESSELAR ${ }^{2}$ sobre o modo de o homem incorporar-se à sociedade:

"Não é um processo mecânico e sim um processo inconcebível sem um certo grau de espiritualidade, isto é, liberdade e originalidade. Sem dúvida, o homem necessita da sociedade para ser verdadeiro homem, mas a sociedade para ser verdadeiramente humana precisa mais ainda do homem, da personalidade; a pessoa humana integra-se na sociedade e transcende-a, ao mesmo tempo. Há sempre uma certa tensão entre a sociedade e a pessoa, por vezes até conflitos trágicos. O homem medíocre escolhe geralmente o caminho do menor esforço, acomodando-se de boa vontade às exigências, justas ou injustas, da coletividade. Se uma grande personalidade se lhe adapta, o faz por motivos bem diferentes. Consciente do seu lugar no conjunto social toma uma livre decisão em virtude de certos valores objetivos que a sociedade representa. Mas acontece também que se revolta contra ela, com seus protestos, seus atos, palavras e atitudes. Insurge-se contra as tendências niveladoras de toda convivência humana.

Por dois motivos merece então a atenção dos historiadores - por seu valor intrínseco e por causa da influência que exerce sobre o processo histórico.

Sir Edward $\mathrm{COOK}^{3}$, biógrafo de Florence Nightingale concorda com este ponto de vista:

"A controvérsia é perene entre os que afirmam que o curso da história política ou social se deve principalmente aos grandes vultos e os que afirmam que se deve, ao contrário, a movimentos sociais ou tendências. Menos controvertida é a afirmação de que os grandes vultos, os que deixam marca mais permanente na história, são aqueles cujo gênio não só se adapta ao espírito de sua época, mas além disso, está à sua frente".

Wanda de Aguiar Horta transmitia esta impressão às pessoas que a conheciam.

Ida Hauss XAVIER ${ }^{12}$, professora da Escola de Enfermagem da UFRS, expressou de maneira carinhosa e eloqüente essa impressão em trabalho apresentado em 1986 na Semana Wanda de Aguiar Horta:

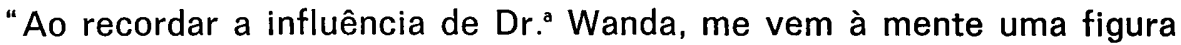
típica do Rio Grande do Sul, o Gaúcho do Pampa.

O Gaúcho do Pampa vê longe no seu território, e a Dr. ' Wanda entrou em nossa imagem como o gaúcho que vê mais longe. A dimensão de seu trabalho é muito grande, difícil de ser compreendida ainda hoje em toda sua extensão".

Transmitir a força e a dimensão do trabalho de Wanda de Aguiar Horta, embora tarefa difícil, é o objetivo da próxima unidade. 


\section{VIDA E OBRA DE WANDA DE AGUIAR HORTA}

Wanda Cardoso de Aguiar nasceu em Belém do Pará em 11 de agosto de 1926.

O sr. Alberico Hesketh de Aguiar e dona Feliz Cardoso de Aguiar tiveram 8 filhos, sendo 5 homens e 3 mulheres. Ela foi a $5 .^{a}$ filha e cresceu em um ambiente de grande harmonia, compreensão e amizade.

Permaneceu em Belém até os 10 anos de idade e foi naquela cidade que realizou seus estudos primários.

Dona Nazareth, uma de suas irmãs mais velhas, forneceu algumas informações sobre sua infância e adolescência.

A menina Wanda, cedo demonstrou possuir uma inteligência privilegiada. Precocemente estudiosa, procurava aprender a essência do que lhe era ensinado e por isso era muito elogiada por seus professores.

Uma das manifestações de sua personalidade marcante era o vocabulário de que fazia uso, preciso e notadamente mais amplo que os das crianças de sua idade.

Muito sensível, introspectiva e até um pouco casmurra, segundo informações de dona Nazareth, era no entanto amiga de todos que a rodeavam.

Dinâmica, procurava diversificar as formas de dar expressão à sua personalidade marcante. Começou cedo a estudar piano, instrumento que viria a tocar com perfeição, além de escrever poesias.

Em 1936 a família Aguiar muda-se para Ponta Grossa, no Paraná.

E nesta fase que sua escolha pela enfermagem começa a se delinear. E a própria Wanda HORTA ${ }^{10}$ que relata período que vai desta época até início de sua vida profissional, em um artigo de 1975.

"Em Ponta Grossa fiz ginásio e pré-médico. As duas outras áreas oferecidas, pré-jurídico e pré-engenharia, decididamente não me atraíam.

O Brasil havia declarado guerra ao Eixo, estávamos em plena mobi. lização militar e preparo do povo para possíveis ataques aéreos. A Cruz Vermelha Brasileira, filial de Ponta Grossa, abriu curso para Voluntários Socorristas, no qual me inscrevi. O curso era à noite, essencialmente teórico e dado por médicos.

Em caravana da Cruz Vermelha, participando da programação de um feriado nacional, fui a Curitiba, onde desfilei cono enfermeira, num uniforme improvisado, sentindo-me como se tudo fosse verdadeiro. Ao regressar, entusiasmada (estava com 16 anos) ao saber que a Força Expedicionária Brasileira teria um corpo de enfermeiras, pedi autorização a meus pais e telegrafei ao Ministro da Guerra, oferecendo-me para integrar a FEB. Não recebi, obviamente em razão da pouca idade, resposta a este telegrama. 
Em 1944, mudamos para Curitiba. Desejava ingressar na Faculdade de Medicina, mas, por motivos financeiros e por não ter ainda a idade requerida para o ingresso, procurei trabalhar e estudar para o vestibular.

Recebi convite de Dona Rosalina Niepce da Silva, diretora do Posto de Puericultura da Legião Brasileira de Assistência, da Praça Carlos Gomes, para trabalhar em atividades de enfermagem. Adquiri, então, os rudimentos da profissão com uma antiga funcionária do posto e com o médico Pediatra, Dr. Waldemar Monastier. Aplicava medicação por todas as vias, fazia provas tuberculínicas, observava as crianças e fui adquirindo, sob a orientação do Dr. Monastier, miutas noções de patologia e pediatria.

No início de 1945, Dona Rosinha N. Silva deu-me para preencher um formulário para uma bolsa de estudos para estudar na Escola de Enfermagem de São Paulo, anexa à Faculdade de Medicina da Universidade de São Paulo. Foi desta maneira que tive conhecimento de que havia escolas onde se estudava enfermagem e onde, como matérias curriculares, teria entre outras, aquelas mesmas - microbiologia, anatomia, fisiologia com as quais me havia entusiasmado ao primeiro contato durante o curso para Voluntárias Socorristas.

A bolsa de estudos, à qual afinal me candidatei, foi dada ao Paraná pelo Serviço Especial de Saúde Pública (SESP), órgão recém-criado pelo governo Federal em colaboração com o governo dos Estados Unidos.

Naquela época, a Escola de Enfermagem se instalava no já famoso Hospital das Clínicas da Faculdade de Medicina da USP.

O curso de enfermagem feito entre julho de 1945 e novembro de 1943 foi para mim contínua fonte de satisfação e aprendizagem.

De dezembro de 1948 a dezembro de 1949, trabalhei em Santarém, no SESP. Este serviço, por sua filosofia de trabalho, deu-me uma perspectiva da enfermagem que se desenvolveu e que conservo até hoje, isto é, que a enfermagem é um todo indivisível, não se fragmenta em compartimentos estanques tal como o homem objeto de sua atenção. No SESP havia trabalho de equipe - médicos, engenheiros, enfermeiros - todos interessados no bem comum: a saúde da população; éramos colegas de trabalho, nos reuníamos e decidiamos quais as medidas a tomar.

O Hospital era também Centro de Saúde, o que hoje se chama Unidade Médico-Sanitária. Os clientes eram acompanhados no Centro e depois no Hospital, caso fossem internados, sem solução de continuidade no seu atendimento. A assistência à população era completa, bem diferente daquela aprendida na Escola, em Enfermagem de Saúde Pública. Trabalhávamos com a população e não para ela. Ali pude ter experiências de aprendizagem tanto no Hospital como no Centro de Saúde e em docência. Fui assistente da Diretora dos Cursos de Visitadores Sanitários e de Auxiliares Hospitalares, lecionando diversas disciplinas com estágio no campo clínico." 
Por motivo de doença na família, em dezembro de 1949, Wanda de Aguiar Horta retorna ao Paraná, e de 1950 até 1954 chefia o serviço de enfermagem do Sanatório Médico Cirúrgico do Portão, Divisão de Tuberculose, da Secretaria de Saúde Pública do Estado do Paraná.

E nesta fase que pode-se localizar a primeira referência bibliográfica do início da trajetória de Wanda de Aguiar Horta na busca de uma prática mais científica e filosófica da enfermagem.

Se trata do artigo "Conceito de Enfermagem" publicado por ocasião do Dia da Enfermagem na Gazeta do Povo, em Curitiba a 12 de maio de 1951.

"Embora a enfermagem seja tão antiga quanto a humanidade, no Brasil pouco se sabe sobre ela.

Em todas as esferas sociais mesmo nas profissões afins, o conceito de enfermagem se resume em dois:

1) Um homem ou mulher de guarda-pó, de véu, touca ou gorro e que sabe aplicar injeção.

2) Imagem poética, um anjo sofredor, heroína do trabalho, na cabeceira do doente, que tudo suporta sem queixa, sem tempo para estudar e progredir na profissão.

O que se faz nestes hospitais não é enfermagem, e sim pseudoenfermagem. $O$ objeto de todas as atenções, a finalidade do serviço tem por centro o médico: servir o doente em relação ao médico. Fazer tudo do melhor modo possível para evitar o aborrecimento do médico. Há uma inversão de valores.

A verdadeira enfermagem tem como objetivo primordial SERVIR O DOENTE e em segundo lugar, AUXILIAR O MÉDICO EM RELAÇÃO AO DOENTE (grifos da autora).

$O$ verdadeiro centro de atenções e cuidados é o doente, em torno do qual médicos, enfermeiros, assistentes sociais, nutricionistas, laboratoristas e demais técnicos, se devem congregar."

E interessante notar que muito antes que o conceito de equipe multiprofissional de saúde fosse incorporado à prática assistencial, o que se dá no início da década de 70 , Wanda Horta o antecipava neste artigo.

Em 1954, com 27 anos, casa-se com o engenheiro Luis Emílio Gouvêa Horta e passa a chamar-se Wanda de Aguiar Horta, ou simplesmente Wanda Horta, que é como ficou conhecida nacionalmente.

Wanda Horta retorna então a São Paulo e trabalha no Hospital Central Sorocabano (1954-55), no Sanatório do Mandaqui (1955) e no Pronto Socorro da Carteira de Acidentes do Trabalho do Instituto de Aposentadoria e Pensões dos Industriários (1955-58).

Retorna à Escola de Enfermagem da USP como docente em 1959. 
Em 1977, no discurso feito por ocasião da solenidade de posse ao Cargo de Professor Titular da Escola de Enfermagem da USP ela iria se referir a este período em que enfrentou as dificuldades do dia a dia dos serviços de enfermagem, antes de retornar à escola.

“Em 1959 retornei a esta casa como docente, já tendo enfrentado durante 10 anos, com colegas ou sozinha, o dia a dia da enfermagem no campo. Quanto aprendi! Quantos erros cometi! Deles procurei tirar ensinamentos, para reconstruir ou revisar conceitos e valores." 5

É na Escola de Enfermagem da USP que Wanda de Aguiar Horta vai desenvolver o núcleo central de seu trabalho que consistiu na elaboração de vasta fundamentação teórica para a enfermagem, culminando com a elaboração da Teoria das Necessidades Humanas Básicas ?.

Esta teoria é considerada o ponto alto de seu trabalho e a síntese de todas as suas pesquisas.

Se a síntese de seu trabalho pode ser considerada a elaboração desta teoria, a origem do mesmo pode ser identificada desde suas primeiras publicações, quando Wanda de Aguiar Horta continua manifestando sua insatisfação pela forma que a enfermagem vinha sendo praticada nos hospitais brasileiros.

Na conclusão do artigo "Aspectos do Conforto do Paciente em Hospital" 5 , de 1964, ela desabafa:

"O que temos podido observar nos hospitais em matéria de conforto ao paciente, não só nos serviços puramente assistenciais e gratuitos, mas até mesmo nos particulares e pagos é tão desanimador que quase nos leva a concluir: "NOS HOSPITAIS OFERECEMOS O MAXIMO DE DESCONFORTO AOS INTERNADOS" (grifos da autora).

A partir desta constatação, Wanda de Aguiar Horta começa a pesquisar soluções. E imenso o volume de artigos que publicou, bem como as pesquisas desenvolvidas, que the possibilitaram alcançar o ponto máximo da carreira universitária, o de Professor Titular da Escola de Enfermagem da USP, em 1977.

Pós graduou-se em Pedagogia e Didática Aplicadas à Enfermagem na Escola de Enfermagem da USP em 1962.

Doutorou-se em Enfermagem pela Escola de Enfermagem Ana Néri da Universidade Federal do Rio de Janeiro, em 1968, com a tese "Observação Sistematizada na Identificação de Problemas de Enfermagem em seus Aspectos Físicos ${ }^{9}$."

Na Escola de Enfermagem da USP alcançou ainda os títulos de Professor Livre-Docente em 1970 e Professor Adjunto em 1974.

Em 1981, ano de seu falecimento, foi proclamada Professor Emérito pela Egrégia Congregação da Escola de Enfermagem da USP. 
Esta escola é o ponto de referência da carreira de Dr." Wanda, mas sua influência alcançou todo o país.

Nas Escolas de Enfermagem das Universidades do Rio de Janeiro, Santa: Catarina e Rio Grande do Sul ela participou ativamente, dando aulas e organizando cursos e orientando pesquisas.

Suas realizações são tantas que se torna impossível enumerá-las.

Para se ter uma idéia, seu Memorial ${ }^{8}$ apresentado para o concurso de Professor Titular em 1977 tem 109 páginas, onde ela procura resumir suas atividades acadêmicas e sua produção científica comprovada através de 408 documentos!

Dele constam conferências em diversos pontos do país e no exterior, organização de cursos de graduação e pós-graduação em diversos estados brasileiros, o comparecimento em atividades culturais no Brasil e exterior, a orientação de diversos trabalhos de pesquisa, participação em inúmeras comissões de estudo e bancas examinadoras. Quando se tratava de promover a enfermagem, sua disposição não tinha limites.

Apresentou conclusões de diversos de seus trabalhos nas reuniões anuais da SBPC, abrindo assim um espaço para a enfermagem na comuhidade científica.

E importante lembrar sua participação na elaboração do Documento Básico sobre o Ensino de Fundamentos de Enfermagem a convite da Organização Panamericana de Saúde e Organização Mundial de Saúde em Washington em 1973.

Este fato demonstra o reconhecimento internacional do valor de seu trabalho, que passa a ser utilizado como marco referencial para a disciplina Fundamentos de Enfermagem nas escolas de enfermagem da América Latina.

Todas estas realizações podem dar a idéia de que havia unanimidade em torno de suas idéias, o que não corresponde à realidade.

Pelo contrário, Wanda de Aguiar Horta enfrentou muitas resistências. As idéias desta pioneira perturbaram os baluartes conservadores da enfermagem. Inúmeras barreiras tiveram que ser vencidas.

Para melhor divulgar suas idéias, criou e manteve de 1975 a 1979, sem o apoio de qualquer órgão oficial, a revista Enfermagem em Novas Dimensões.

Esta publicação se tornou um marco editorial da enfermagem brasileira. Era uma revista dinâmica, de diagramação moderna, voltada para a divulgação e o estímulo à pesquisa científica na comunidade da enfermagem.

Sua força residia na certeza que tinha de seus objetivos. Transformar a enfermagem executora de tarefas e centrada na doença em uma enfer- 
magem baseada no método científico e voltada para o ser humano total foi a enorme tarefa a que se propôs.

Suas armas nesta batalha foram sua inteligência viva, seu carisma pessoal, sua disposição sem limites e seu entusiasmo pela enfermagem.

Durante os dez últimos anos de sua vida, mesmo doente, permaneceu trabalhando pois só assim sabia viver.

Atravessou momentos difíceis, vítima de uma doença degenerativa, a esclerose múltipla, tendo vivido os últimos anos de sua vida em cadeira de rodas.

Seus últimos manuscritos demonstram que as mãos já não obedecem, as letras saem trêmulas - passa então a gravar suas idéias, aumentando assim seu vasto acervo.

Com certeza somente daqui a alguns anos o trabalho de Wanda de Aguiar Horta poderá ser avaliado.

Gente que cuida de gente - assim ela definiu enfermagem. E para ela, ser gente era sentir-se responsável pelo destino da humanidade.

$\mathrm{Na}$ sua busca de bases teóricas para a profissão, Wanda Horta jamais esqueceu a dimensão humana da enfermagem. $O$ trabalho se encerra com uma poesia de Wanda Horta, que bem demonstra esta dimensão.

\title{
VIGILIA
}

\author{
W. A. HORTA \\ 07/03/74
}

A madrugada está chegando,

o plantão terminando.

A noite foi comprida

como os corredores,

onde as pernas cansadas

agora se arrastam,

atendendo a luzes

que se acendem e apagam,

a gemidos,

gritos abafados, sorrisos fatigados.

Muito obrigado,

olhares agradecidos,

mãos que buscam a outra

num apertar silencioso, mas tão eloqüente.

$\mathrm{O}$ primeiro choro do recém-nascido,

o último estertor daquele que parte

em paz para a eternidade. 
E as pernas se arrastam, num ir e vir, sem cessar ainda há tanto para fazer, atender, escrever!

O sol surge de leve

e pouco a pouco

o dia se anuncia.

Ao longe, no corredor, surge,

de branco, impecável, serena e segura

irradiando

saber, ternura,

confiança,

esperança,

a enfermeira do dia.

O plantão terminou!

GONÇALVES, J. V. Wanda de Aguiar Horta - Biography. Rev. Esc. Enf. USP, São Paulo, 22 (special issue): 3-13, June 1988.

This paper's is to reconstitute the main facts in the professional life of Wanda de Aguiar Horta. She, as a nurse and an educator has revolutionized the conceptual structure of brasilian nursing. As a introduction, a bibliographic revision of biographic style has been made.

UNITERMS: Wanda de Aguiar Horta. Biographee.

\section{REFERENCIAS BIBLIOGRAFICAS}

1. AGUIAR, W. de. Conceito de enfermagem. Gazeta do Povo, Curitiba, 12 maio 1951.

2. BESSELAR, Van den. Introdução aos estudos históricos. São Paulo, EPV, 1974.

3. COOK, E. The life of Florence Nightingale. New York, Mcmillan, 1942.

4. ENCYCLOPAEDIA BRITANNICA. Biography. Chicago, Enciclopaedica Britannica, 1944. v. 3. 593-598.

5. HORTA, W. de A. Aspectos do conforto do paciente em hospitais. Rev. Bras. Enf., Rlo de Janeiro, 17(3/4):114-8, 1964.

6. HORTA, W. de A. Discurso de agradecimento. Rev. Esc. Enf. USP São Paulo, 12(1): 13-6, abr. 1968.

7. HORTA, W. de A. Enfermagem: teoria das necessidades humanas básicas. Enf. Novas Dimens., São Paulo, 5(3):133-6, 1979.

8. HORTA, W. de A. Memorial apresentado à egrégia Congregação da Escola de Enfermagem da USP para Concurso de Professor Titular. São Paulo, 1977.

9. HORTA, W. de A. Observação sistematizada na identificação de problemas de enfermagem em seus aspectos físicos. Rio de Janeiro, 1968. (Tese de doutorado Escola de Enfermagem Ana Neri da UFRJ).

10. HORTA, W. de A. Subsídio para a história da enfermagem no Estado do Paraná. Rev. Bras. Enf., Rio de Janeiro, 28(2):60-64, abr./jun. 1975.

11. STRACHEY, L. Victoriens Eminents. 5. ed. Paris, Librairie Gallimard, 1933.

12. XAVIER, E.H. Influência de Wanda de Aguiar Horta na enfermagem brasileira. Trabalho apresentado na SEMANA WANDA DE AGUIAR HORTA, 1.․, São Paulo, 1986. 